\title{
Knowledge Creation and Sharing Process Enhanced by Cloud-Based Tools, Anno- tation Technology and Open Data
}

\author{
Milena Krumova \\ Technical University - Sofia Bulgaria \\ bul.Kl.Ohridksi 8 \\ mkrumova@tu-sofia.bg
}

\begin{abstract}
The aim of the research is to present a new approach for Knowledge Creation and Sharing Process (KCSP). The paper is organized as follow. The introduction outlines some technology trends in educational innovations and the role of the innovative pedagogy and Learning 3.0. Part i) presents a Knowledge Creation and Sharing Process, an interdisciplinary approach is applied. Part ii) is centered around cloud-based tools, in iii) the annotation approach is discussed and in iv) open data and how they can be utilized as a part of an innovative smart learning process. Part v) explains a proposed KCSP 3.0 model and its implementation. The conclusion outlines lessons learned and future research steps towards the use of data generated through the Learning Management System (LMS) and cloud-based tools and how educational data mining to be used for better understanding how learners learn.
\end{abstract}

Keywords: Cloud Technology, Knowledge Creation, Annotation, Open Data, Learning 2.0

Received: 13 April 2018, Revised 18 May 2018. Accepted 21 May 2018

DOI: $10.6025 / \mathrm{jet} / 2018 / 9 / 3 / 73-81$

(C2018 DLINE. All rights reserved

\section{Introduction}

Education is dynamically evolving, thanks to the incredible achievements in highly powerful and intelligent tools and technologies that are rapidly emerging. Online learning models encourage students to be more active participants in their own learning allowing them to not just be knowledge consumers, but knowledge creators as well. In the context of technologies, numerous teaching and learning models have been developed and taxonomies to teach students the techniques of creative and productive thinking. A value can be added to such a process by the advancement of social media tools and web 2.0 and learning 2.0 models, which allow learning to be far more engaging, challenging and foster social interactions (Gradis and Tiffini, 2014). Learning 3.0 has been discussed as the next generation learning model having four key drivers: distributed computing, extended smart mobile technology, collaborative intelligent ûltering, 3D visualization and interaction (Rubens, et al., 2011; Hussain. 2012). The implementation of web 3.0 within learning process possesses huge potential to change the way learning occurs and interaction among learners while develop their creativity, inspiration and foster knowledge creation and sharing. Even though the numerous studies have been devoted to the technology enhanced learning (Sudeep, 2013; Ghuloum, 2010), learning 2.0 (Selwyn, et al., 2008) and learning 3.0 (Rubens, et al., 2011), none of them explains how the open data and cloud technology can be implemented within the 
learning 3.0 model thus change the way the learning occurs. Knowledge creation and social interaction (Nonaka and Takeuchi, 1995 ) within the learning process can be mediated not only by cloud-based technology, but also by the open data. A diversity of approaches is applied for the purpose to be improved the learning process, such as innovative pedagogy, technologies, methodologies, learning spaces. An innovative pedagogy is not only the open collaborative working spaces (Ferguson, R., et.al.), learning "coffees" and non-formal learning moles, but also the model of interactions among the learners and teachers. The cloud-based technology possesses a great potential to transform education and learning (UNESCO; Her shock and. LaVaqueManty, 2012). Within the technology-enhanced learning ecosystem there are much more possibilities for learning process innovations, not only by utilizing web 2.0/3.0 tools but also by utilizing the annotation tools. Research studies show that annotation technologies can be involved very well in the deployment of online courses (Nunes, B.P. et. al). This research paper tries to answer the question of how cloud technologies, annotation tools and open data can be embedded into learning thus foster knowledge creation and sharing process.

\section{Knowledge Creation and Sharing}

The interactions between the explicit and tacit knowledge lead to the creation of new knowledge. The combination of the two categories makes it possible to conceptualize four conversion patterns Nonaka's SECI model major phases (Socialization Externalization - Combination - Internalization) (Nonaka \& Takeuchi, 1995):

- Socialization is the process of sharing tacit knowledge through observation, imitation, practice, and participation in formal and informal communities. The socialization process is usually preempted by the creation of a physical or virtual space where a given community can interact on a social level.

- Externalization is the process of articulating tacit knowledge into explicit concepts. Since tacit knowledge is highly internalized, this process is the key to knowledge sharing and creation.

- Combination is the process of integrating concepts into a knowledge system (Yeh et al., 2011).

- Internalization is the process of embodying explicit knowledge into tacit knowledge.

The knowledge creation and sharing process can be also very well explained as an analogy of the Seasons in Nature, see Figure 1. The knowledge creation process starts when the learner receives the explicit knowledge "Winter". These are books, URL resources to read, statistics, etc. The second stage starts with the learning activities such as reading, analyzing, resuming, or another learning activity, when the knowledge content is used "Spring". The main element is the process of reflection. It happens when the knowledge transformation starts and explicit knowledge is converted to tacit. The third stage is "Summer" when the learner created the new knowledge and then tacit knowledge is converted to explicit knowledge. This explicit knowledge can be projects, presentations, talks, discussions and many other. The final stage is the sharing of knowledge when the newly created knowledge as analyses or reports "Autumn", or another artifact - digital resource, depending upon the learning assignment and knowledge area. The explicit knowledge is shared among the learning community - teachers and peers.

\section{Cloud-based Tools in Learning}

Cloud-based tools or applications are online or web-based applications that are accessible generally via a web browser. They range from basic websites to complex and highly interactive online learning environments. Many are free for education or may have basic versions which are free, while possibly charging for more advanced functionality (Cloud based tools, 2015). Educational organizations of all sizes utilize a diversity of cloud-based tools, web 2.0 and Social media technologies for many uses and internally to increase collaboration, communication and informal learning. Web 2.0refers to the range of digital applications that enable interaction, collaboration and sharing between users. According to their learning functions, web 2.0 can be classified into five categories (See Table 1) (Mbarika et. al). Tools range from free, basic applications to subscription-based, more in-depth tools.

By utilizing web-based tools, the Learning 2.0 can contribute to making educational organisations more dynamic, flexible and open. It can help Education and Training institutions to become reflective organisations that critically evaluate and revise their learning strategies in order to support innovative pedagogies. Education and training organisations have to make sure they provide an infrastructure in which social media tools are accessible to all learners and teachers, create an atmosphere of support for Learning 2.0, foster and integrate new teaching and learning models; and be open to new assessment and grading strategies 


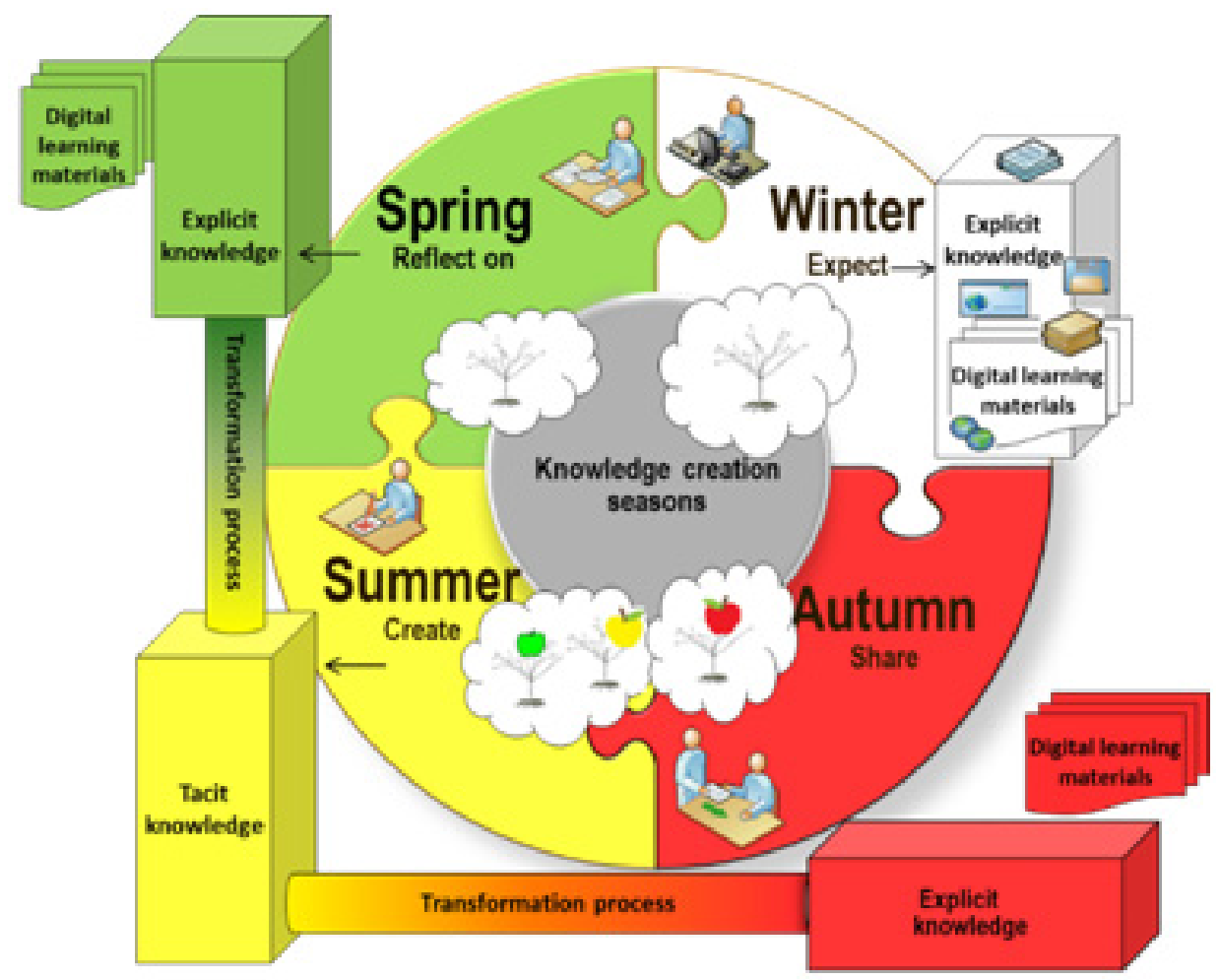

Figure 1. Knowledge Creation and Sharing Process - Seasons in Nature Metaphor Model

\begin{tabular}{|c|c|c|c|}
\hline Type & Function & Tools & Web applications \\
\hline Communicative & $\begin{array}{l}\text { To share ideas, information, } \\
\text { and creations }\end{array}$ & $\begin{array}{l}\text { Social networking, Blogs, Au- } \\
\text { dio blogs, Video blogs, IM } \\
\text { tools, Podcasts and Web- } \\
\text { conferencing }\end{array}$ & $\begin{array}{l}\text { Tumblr, Moovly, Blogger, YouTube, } \\
\text { MySpace, Twitter, BumpIn, Vidipedia } \\
\text { etc. }\end{array}$ \\
\hline Collaborative publishing & $\begin{array}{l}\text { To work with others for a } \\
\text { specific purpose in a shared } \\
\text { work area }\end{array}$ & $\begin{array}{l}\text { Authoring, Editing tools, Virtual } \\
\text { communities of practice } \\
\text { (VCOPs), Wikis }\end{array}$ & $\begin{array}{l}\text { Wikipedia, Vidipedia, Netcipia, } \\
\text { Wordpress, PBworks, Flipsnack, } \\
\text { Anymeeting }\end{array}$ \\
\hline $\begin{array}{l}\text { Documentative } \\
\text { (content management) }\end{array}$ & $\begin{array}{l}\text { To collect and/or present evi- } \\
\text { dence of experiences, think- } \\
\text { ing over time, etc. }\end{array}$ & $\begin{array}{l}\text { Blogs, Videoblogs, E-portfolios, } \\
\text { Open Journalism }\end{array}$ & $\begin{array}{l}\text { ClassMaker, SeeNReport, Calameo, } \\
\text { Drupal, MindMeister }\end{array}$ \\
\hline Generative & $\begin{array}{l}\text { To create something new } \\
\text { that can be seen and/or used } \\
\text { by others }\end{array}$ & $\begin{array}{l}\text { Mashups, VCOPs, Virtual } \\
\text { Learning Worlds (VLWs) }\end{array}$ & Second Life, Flickr, YouTube, Pixton, \\
\hline Interactive & $\begin{array}{l}\text { To exchange information, } \\
\text { ideas, resources, materials }\end{array}$ & $\begin{array}{l}\text { Social bookmarking, RSS, } \\
\text { VCOPs, VLWs }\end{array}$ & $\begin{array}{l}\text { TypoEffect, StumbleUpon, Delicious, } \\
\text { Facebook, MySpace, Animoto, } \\
\text { QuestionPro }\end{array}$ \\
\hline
\end{tabular}

Table 1. Web 2.0 tools and functions 
(Redecker, 2010). Among most popular web 2.0 tools for learning are: Blogging; Collaborative calendaring; Podcasting; RSS readers; Collaborative mind mapping; Micro-blogging/micro-sharing; Photo sharing; Screen cast sharing; Presentation sharing; Video sharing; Social bookmarking; Collaborative editing; Collaborative working; Collaborative presentations; Social networking; Personalized start pages; Integrated social/collaboration environment; etc. Unlike web 2.0, web 3.0 is a complete reinvention of the web.Learning takes place from the teacher to student, student to student, and student to teacher. For example, collaborative whiteboards such as Padlet allow information, links, images, and videos to be posted simultaneously.

\section{Annotation Tools}

Annotations are social software tools that allow users to add, change or remove data from a knowledge resource without modifying the original content of the web page thus add values to the learning progress and mainly knowledge creation and sharing (Figure 2). Annotating a text can be a powerful strategy to comprehend difficult material and encourage active reading. Research shows that examining and analyzing models of annotated texts have been successful ways for students to see what can be done when using annotation as a reading strategy. Annotating helps readers reach a deeper level of engagement. It makes the reader's "dialogue with the text" a visible record of the thoughts that emerge while making sense of the reading. Examining and analyzing models of annotated texts have been successful ways for students to see what can be done when using annotation as a reading strategy (Porter-O'Donnell, C., 2014).Several tools that can help students and teachers in the learning process. In this manner, a simple yet powerful annotation tool, that has demonstrated a huge potential to improve and facilitate the learning process and course management (Nunes, B.P. et. al). Text annotation have several advantages for learning process: improve learners ' concentration; provide an immediate self-check for understanding of the text's key ideas; help learners' remember more; assist and negate the need of time spent in rereading the learning content; generator of ideas.

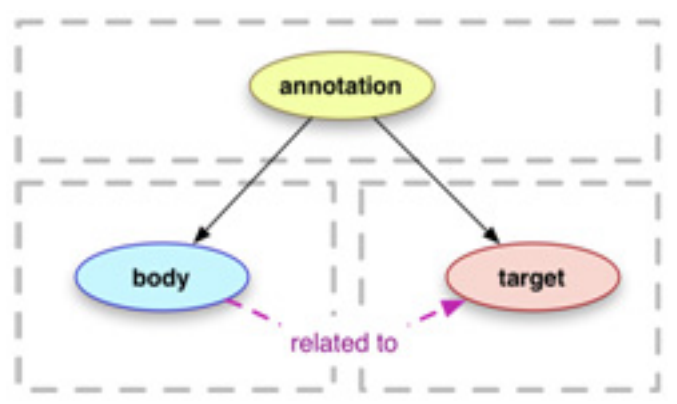

Figure 2. Web Annotation Data Model

Using annotations the learner can formulates questions, analyzes and interprets elements and draws conclusions and makes inferences based on explicit and implicit meaning. Annotation tools allows student participation in an online annotation system that allows students to discuss the reading online collaboratively (Miller, K. et. al, 2016).

\section{Open Data and Learning}

Open data is data that can be freely used, re-used and redistributed by anyone - subject only, at most, to the requirement to attribute and sharealike (Open Data Handbook). Data that is truly open is: accessible (ideally via the internet) at no more than the cost of reproduction, without limitations based on user identity or intent, in a digital, machine-readable format for interoperation with other data and free of restriction on use or redistribution in its licensing conditions. Open datausually refers to public records (e.g. on transport, infrastructure, education, and environment)(Digital Agenda, EC).

Some open data usage within the teaching-learning process includes: open data is related to practice; there is a huge amount of open data to develop a diversity of skills ( $Z$ generation + ); open data allows the implementation of an interdisciplinary approach in the learning process; open data is growing; open data are free; open data are source for innovative projects of students; open data are applicable to every knowledge area.

The researches show that open data in education are discussed mainly in the context of the open courses (MOOC), linked open data (LinkedUp), open curriculum (Mikroyannidis, et al. 2014), but not regarding the knowledge domain of the open datasets. For example, the available dataset on open data portals can be explored in a knowledge domain for learning purposes (open data 
for registered companies can be used by students studying business; open data for government spending can be utilized by students at e-government course; open data for hospitals and GP workforce can be used for the purpose of health studies, etc.) while linking the learning to the real practice examples and broaden possibilities for intensify the students' creativity.

\section{Knowledge Creation and Sharing Process 3.0 Model}

Learning must be meaningful and appropriate. The precondition for the practical implementation of the proposed KCSP 3.0 model is LMS environment. Such LMS can be Open Source Software or cloud-based LMS. Examples for Open Source Software are ILIAS, Moodle, etc. Examples for Cloud-Based Learning Management System are Stile LMS, PBworks, Edomodo LMS, etc. The KCSP 3.0 model includes three basic elements (See Figure 3), as follows:

- Cloud-based tools (library of such tools: Moovly; Comix tool - Pixton; Voci; Animoto; etc.)

- Annotation technology(Perusal; etc.)

- Open data (Open data: Open data portals, World bank data portal; etc.)

The KCSP 3.0 model also include the learners' instructions and e-portfolio. The instructions are given at the beginning of the learning process. When an assignment is given, the learners are expected to perform the learning activities and to share the learning outcome through the use of e-portfolio. During the learning process two or more assignments can be given. The number of the assignments can vary.

The learner had to follow the given instructions for each assignment:

- Read/Listen to/ the given knowledge resource from the course related topic - Explicit knowledge has to be given (Winter);

- Reflect on/Analyze/ the knowledge content and propose an idea how to transform/present/ it in a new way - Explicit knowledge is expected to be transformed to Tacit Knowledge (Spring);

- Use the cloud based tool/Annotation tool to present the studied topic in a new digital knowledge resource (for ex. Conceptual map; speaking avatar; Moovly multimedia; etc.) - Tacit Knowledge is expected to be transformed to Explicit knowledge (Summer);

- Share the created digital resource related to the studied topic of the course with peers and teacher - Explicit knowledge was shared (Autumn).

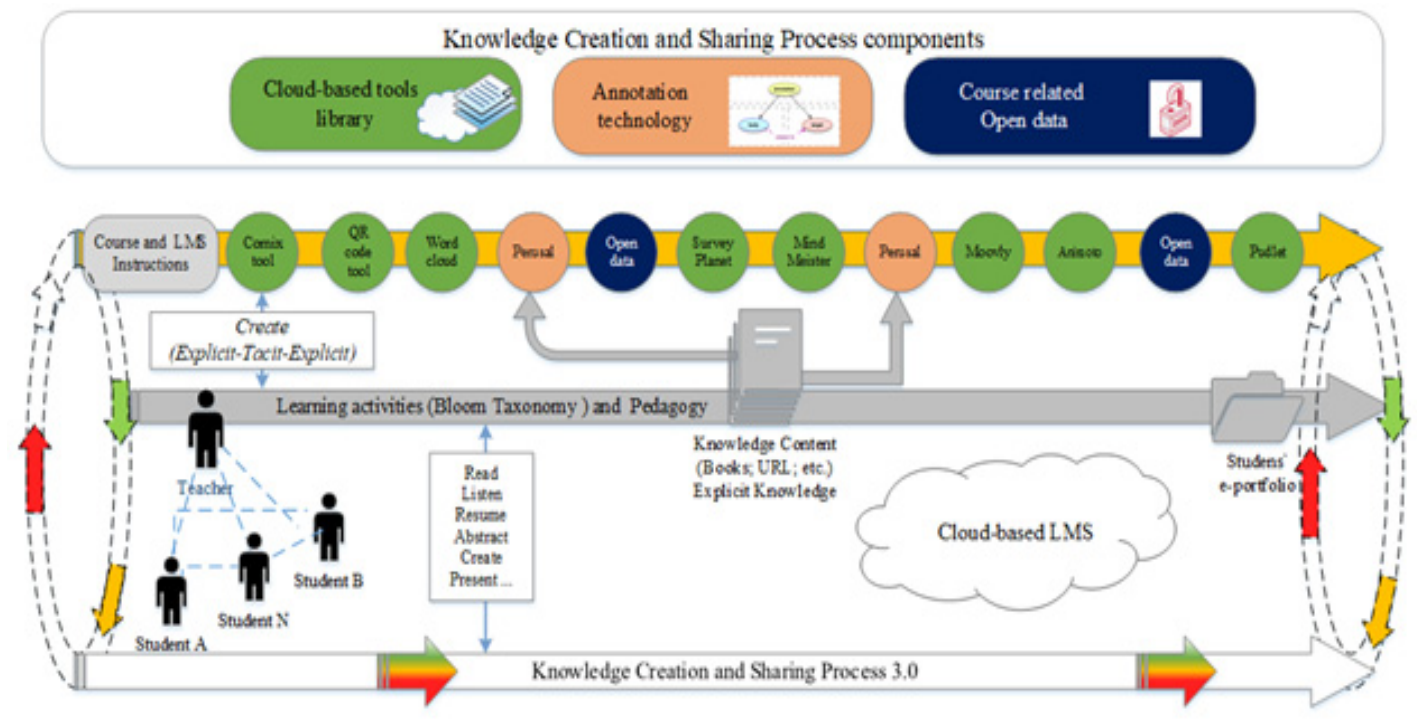

Figure 3. KCSP 3.0 Concept Model 
The implementation of KCSP 3.0 Concept Model has been done during the first semester of 2016/2017 school year at the Technical University - Sofia. Some web 2.0 and web 3.0 tools were used while the attention was put on the personalization of the learning. Students from two courses were involved. One group (230 students) is a bachelor's degree students in their first year of study, the course is Economics. The second one is a group (17 students) of master's degree students in course Information Technologies in Organizations. For the purpose of the concept model implementation, the learning process was organized and conducted within Stile LMS, Figure 4a) and 4b).



Figure 4a. Stile LMS screenshot - Instructions



Figure 4b. Stile LMS Screenshot - Students' assignment

The learning process was organized into four stages:

- $1^{\text {st }}$ - Instructions about the course and the use of the LMS Stile were presented in front of the students;

- $2^{\text {nd }}$ - Conducting the learning during the semester;

- $3^{\text {rd }}$ - Final presentations and students' assignments were collected by them at the students e-portfolio;

- $4^{\text {th }}$ - Final assessment was done using the Stile mark functionality (Figure 6).

Every student has to perform the given assignment within a given deadline. Open data was introduced during the first and second half of the semester (Fee Figure 3). Each of the students has to decide on her/his own way how to link the open datasets from the 
data portal with the studied topic of the course. For this purpose, the students were instructed to get to know what open data are available on the data portal and how they can be utilized. Figure 5a) shows the open data assignment. The annotation tool Perusal aimed at deeper learning process and intensify the knowledge creation process. The students had to interact with the given resource and to ask and reply to their peers' questions. On Figure $5 \mathrm{~b}$ ) it is presented the analytical functionality of Perusal. The analytics shows at what time the learners learn, how much time they spend on each page of the given knowledge resource, etc. valuable data about the learning process itself.

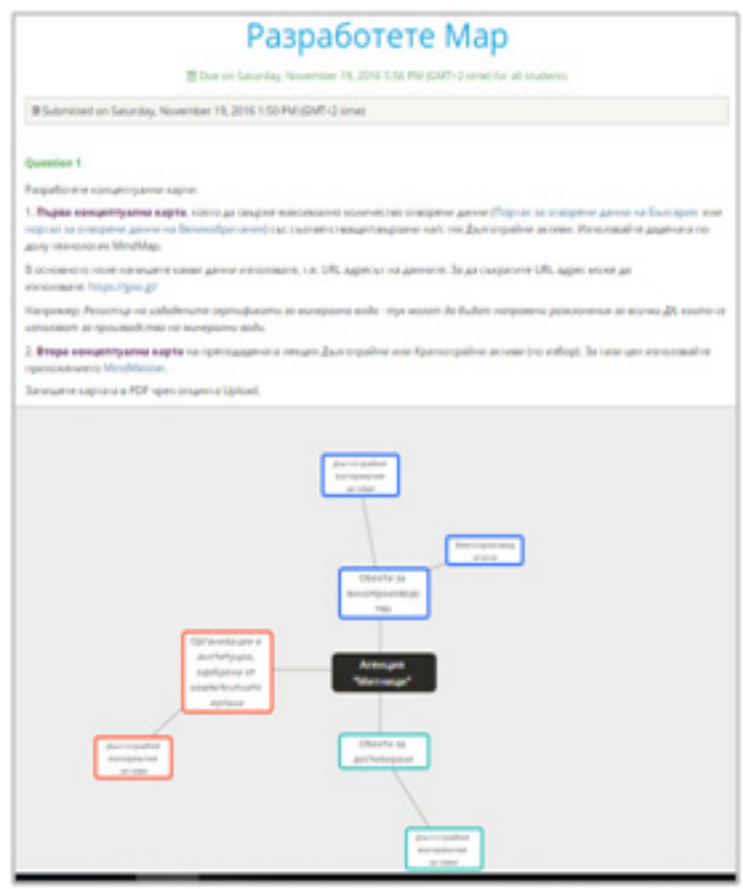

Figure 5a. Stile LMS screenshot - Open data assignment
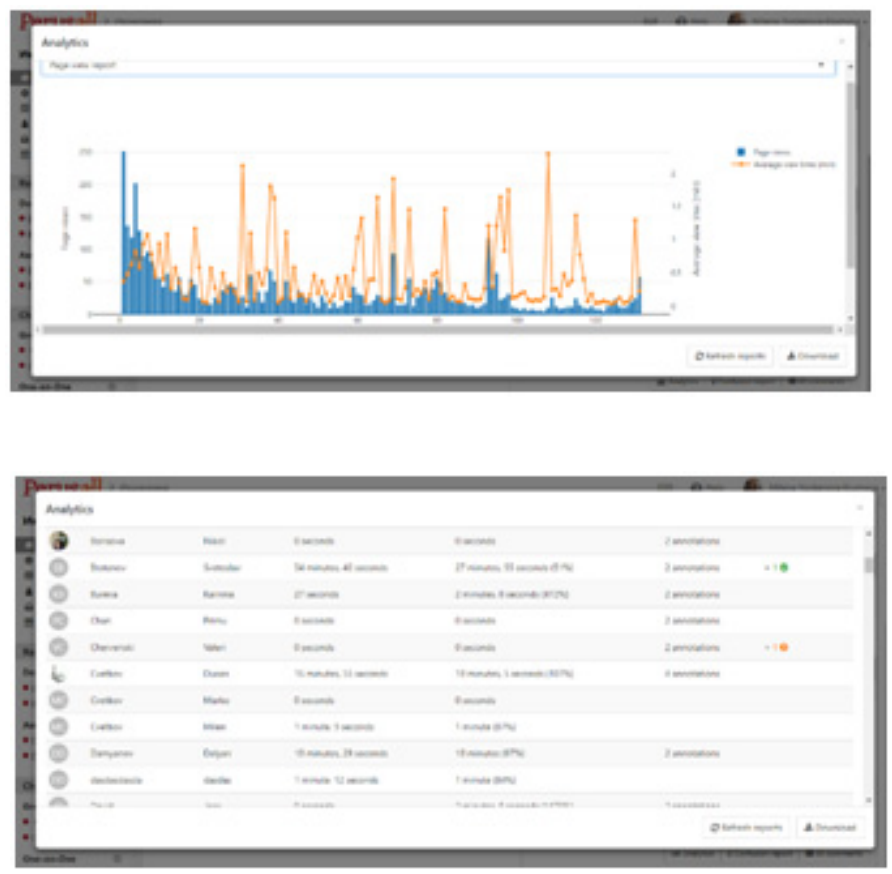

Figure 5b. Annotation tool Perusal - reports

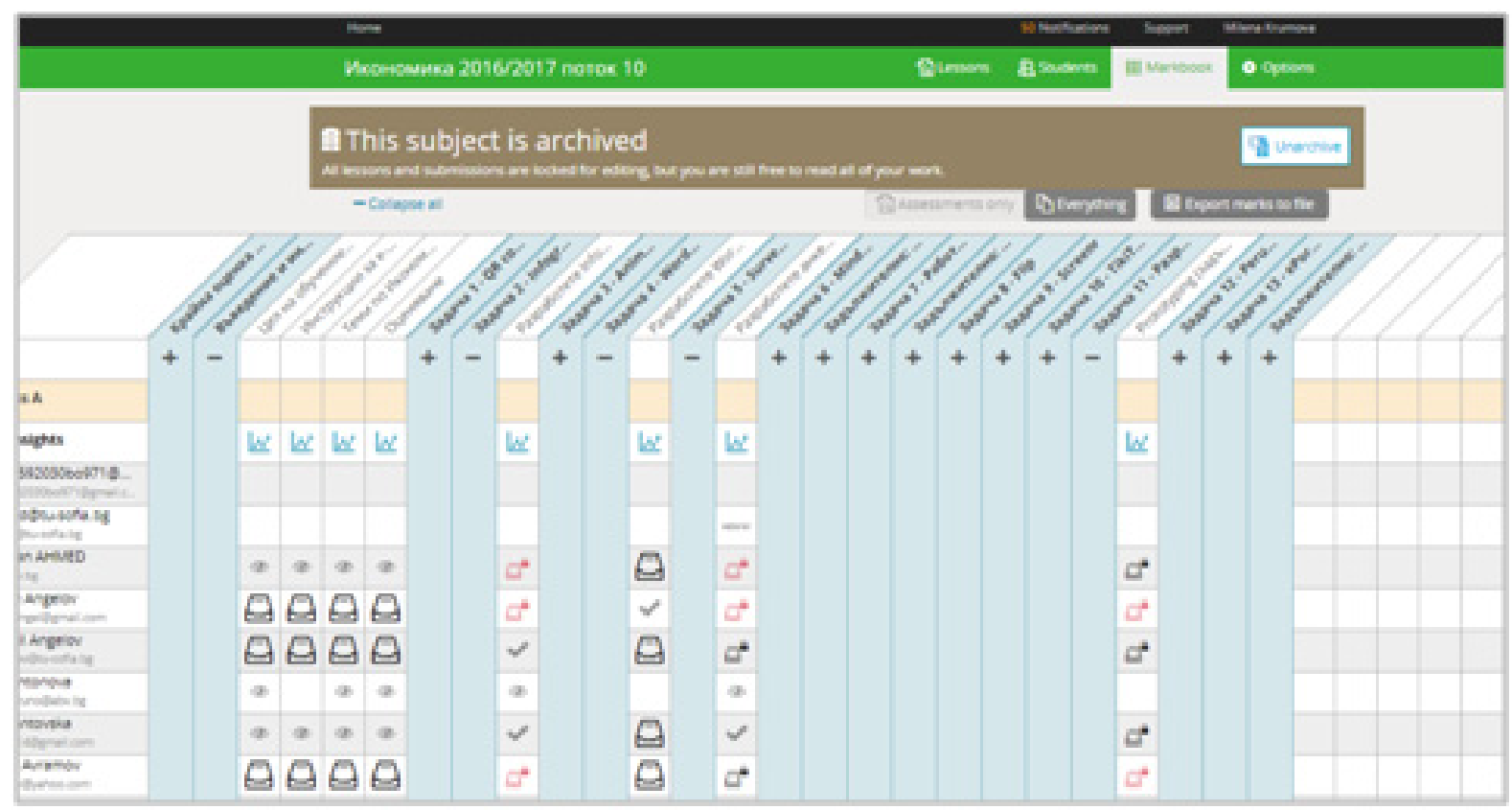

Figure 6. Stile LMS screenshot - Students‘ mark book 
Today's collective consumption of knowledge has changed because of technology, learners need to be able to create it, use it, search it, and share it. The potentials of Web 3.0 and Learning 3.0 are enormous and some of the biggest advantages are related to knowledge creation and sharing process. Cloud-based tools can be utilized for learning innovations, while open data can enrich the learning 3.0 process and give the learner a diversity of alternatives for exploring data for real practices related to a specific domain of knowledge.

\section{Conclusion}

The novelty of this research is, on the one hand, the analogizing the Knowledge Creation and Sharing Process to Seasons in Nature model and the try to find the common characteristics of how the knowledge transformations occur within the learning process. On the other hand, the advancement of the research is the proposed KCSP 3.0 Model, which is based on the three elements - cloud-based tools, annotation technology and open data. The practical implementation of the KCSP 3.0 model shows that the knowledge creation and sharing process can be intensified while brings values to the learners' digitals skills, conceptual thinking, and analytical skills. Moreover, the annotation tools integrated into such learning process can help harness explicit knowledge, build coherent knowledge and speed up learning. This paper contributes the knowledge domain with the implementation of the open data in the innovative learning process thus synergies the learners' curiosity to explore open data and creativity to find a novelty way for data usage. By studying how learners learn based on data gathered through LMS, but also through data gained through technology such cloud-based tools, annotations and going beyond with exploring technology such as visual recognition, video annotations and sound analyses and more, a new knowledge discovery can bring much preciseness about understanding how the learners learn and the knowledge transformation process itself. Following the lessons learned by implementing KCSP 3.0 model, the next research step will be focused on the implementation of data mining based on the data gathered and understanding what cloud-based tools best fit the learners need.

\section{References}

[1] Cloud based Tools \& Applications for Learning, PDST Technology in Education, March 2015, https:// www.pdsttechnologyineducation.ie/en/Technology/Advice-Sheets/Cloud-based-Tools-and-Applications.pdf

[2] Digital Agenda: Turning government data into gold, Last update: 19-02-2018, European Commission - Press release, http:/ /europa.eu/rapid/press-release_IP-11-1524_en.htm

[3] Ferguson, R., Barzilai, S., Ben-Zvi, D., Chinn, C.A., Herodotou, C., Hod, Y., Kali, Y., Kukulska-Hulme, A., Kupermintz, H., McAndrew, P., Rienties, B., Sagy, O., Scanlon, E., Sharples, M., Weller, M., Whitelock, D. (2017). Innovating Pedagogy 2017: Open University Innovation Report 6. Milton Keynes: The Open University, UK. https://iet.open.ac.uk/file/innovating-pedagogy2017.pdf

[4] Ghuloum, H. (2010). 3D Hologram Technology in Learning Environment, Proceedings of Informing Science \& IT Education Conference, http://proceedings.informingscience.org/InSITE2010/InSITE10p693-704Ghuloum751.pdf

[5] Gradis, J., T.Tiffini (2014) Information literacy + Service Learning = Social Change. Paper presented at: IFLA WLIC 2014 Lyon - Libraries, Citizens, Societies: Confluence for Knowledge in Session 166 - Social Science Libraries withWomen, Information and Libraries Special Interest Group. In: IFLA WLIC 2014, 16-22 August 2014, Lyon, France

[6] Hershock, C., LaVaque-Manty, M. (2012) Teaching in the cloud: leveraging online collaboration tools to enhance student engagement,http://www.crlt.umich.edu/sites/default/files/resource_files/CRLT_no31.pdf

[7] Hussain, F. (2012) E-LEARNING 3.0 = E-LEARNING 2.0 + WEB 3.0?, IADIS International Conference on Cognition and Exploratory Learning in Digital Age, http://files.eric.ed.gov/fulltext/ED542649.pdf

[8] Mbarika, V., C. Thomas, P.Tittenberger, When Web 2.0 becomes an organizational learning tool: evaluating Web 2.0 tools, Richard Boateng, http://dailytekk.com/2012/04/09/edtech-100-tech-tools-for-teachers-and-students/

[9] Mikroyannidis, A. et al. (2014) Developing a Curriculum of Open Educational Resources for Linked Data, http:// conference.oeconsortium.org/2014/wp-content/uploads/2014/04/Paper_15-Curriculum.pdf

[10] Miller, K. et. al. (2016) Analysis of student engagement in an online annotation system in thecontext of a flipped introductory physics class, PHYSICAL REVIEW PHYSICS EDUCATION RESEARCH 12, 020143 (2016), DOI: 10.1103/

Journal of E-Technology Volume 9 Number 3 August 2018 
PhysRevPhysEducRes.12.020143, https://pdfs.semanticscholar.org/c3e9/eb7dceaa929a75089704aed1ed47c55073ef.pdf

[11] Nonaka, Ikujiro., Takeuchi, Hirotaka. (1995), The knowledge creating company: how Japanese companies create the dynamics of innovation, New York: Oxford University Press, p. 284, ISBN 978-0-19-509269-1

[12] Nunes, B.P. et.al. Annotation Tool for Enhancing E-Learning Courses, https://pdfs.semanticscholar.org/df61/ 300c6330516158081cedb35d4e9b4428db36.pdf

[13] Open data handbook, http://opendatahandbook.org/guide/en/what-is-open-data/

[14] Porter-O'Donnell, C. (2014) Beyond the Yellow Highlighter: Teaching Annotation Skills to Improve Reading Comprehension, English Journal, National Council of Teachers of English, 93 (5), May 2004, http://www.collegewood.org/ourpages/auto/2014/8/ 17/63598523/Beyond\%20the\%20Yellow\%20Highlighter.pdf

[15] Redecker, C., Ala-Mutka, K. Punie, Y. (2010) Learning 2.0 - The Impact of Social Media on Learning in Europe, European Communities, http://www.ict-21.ch/com-ict/IMG/pdf/learning-2.0-EU-17pages-JRC56958.pdf

[16] Rubens, N., Kaplan, D., Okamoto, T. (2011) E-Learning 3.0: anyone, anywhere anytime, and AI. In International Workshop on Social and Personal Computing for Web- Supported Learning Communities (SPeL 2011), http://activeintelligence.org/wpcontent/papercite-data/pdf/elearning-30-rubens-spel-2011—preprint.pdf

[17] Selwyn, N. et al. (2008) Education 2.0? Designing the web for teaching and learning, London Knowledge Lab University of London, http://www.tlrp.org/pub/documents/TELcomm.pdf

[18] Sudeep, U. (2013) Use of 3D Hologram Technology in Engineering Education, IOSR Journal of Mechanical and Civil Engineering (IOSR-JMCE), 4, http://www.iosrjournals.org/iosr-jmce/papers/sicete(mech)-volume4/43.pdf

[19] UNESCO (2010) Cloud Computing in Education, http://iite.unesco.org/pics/publications/en/files/3214674.pdf

[20] Yeh, Y. C., Huang, L.Y., Yeh, Y. L. (2011). Knowledge management in blended learning: Effects on professional development in creativity instruction, Computers \& Education, 56, 146-156. 